\title{
OPTIMIZING COMPRESSION ZONE OF FLANGED HOLLOW CORED CONCRETE BEAMS USING MOMENT OF INERTIA THEORY
}

\author{
0. Orie ${ }^{1^{*}}$ and B. Idolor ${ }^{2}$

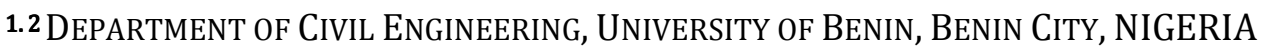 \\ Email addresses: ${ }^{1}$ ogheneale@yahoo.com, ${ }^{2}$ dolorbrume@gmail.com
}

\begin{abstract}
This paper evaluates the optimal cored section of a hollow concrete beam by observing the effect of varying effective flange width and the hollow core position in the compression zone of a plain concrete beam with a point loaded at midspan. Equations were derived using double integration method to determine the moment of inertia of the sections and corresponding deflections as the load increased up to failure, while maintaining a constant crosssectional area and varying the section dimensions randomly in steps of $10 \mathrm{~mm}$ from $150 \mathrm{~mm}$ to $190 \mathrm{~mm}$ flange width. The results obtained were compared with linearized experimental results. The results showed an increase in the deflection with failure loads of the beam samples as the flange width increased. This study reveals that the $150 \mathrm{~mm}, 160 \mathrm{~mm}, 170 \mathrm{~mm}, 180 \mathrm{~mm}$ and $190 \mathrm{~mm}$, flanged beams had a linear coefficient of 5.25, 9.90, 3.87, 10.62 and 7.23 respectively, and thus concludes that the beam with $170 \mathrm{~mm}$ flange width, $46 \mathrm{~mm}$ core position and $0.58 \mathrm{~mm}$ deflection at failure of load $15 \mathrm{kN}$ is the optimal section. This optimal section corresponds to a beam with a flange width $126.67 \%$ its beam width while the core position is about $30.67 \%$ into the compression zone which is measured from the remote edge of the flange. Flanged hollow core beams are commonly encountered in high rise structures and bridges.
\end{abstract}

Keywords: hollow core, flanged concrete beams and optimal failure load.

\section{INTRODUCTION}

A hollow core beam is a horizontal structural member having a void running through its longitudinal axis and carries load primarily in flexure [1]. With the introduction of a flange, the cross-sectional area and volume of the beam section is increased and the geometry of the section is changed. Therefore their structural behavior needs to be understood through investigation to assure their structural integrity.

Maximizing structural efficiency of the strength-mass and stiffness-mass ratios and the desire to reduce the mass or weight contribution of the beam on foundations evolves the need to use hollow sections. A large number of existing bridges have hollow members. Introduction of hollow cores into sections obviously results in larger flexural strength and stiffness than solid members [2]. It may be economical to use hollow reinforced horizontal members to keep to a minimum, the weight and cost of concrete members in some situations [3].
The effect of varying the position of hollow cores in the compression zone of a concrete beam has been investigated [4]. The result of the investigation showed that there was no significant variation in the ultimate failure load. Also, analysis of the result obtained showed that moving the hollow core in a rectangular concrete beam to the topmost fiber could be allowed for economic design only up to $10 \mathrm{~mm}$ or $10 \%$ of half the beam depth, whichever is lesser [4]. In this study, the effect of position and diameter of hollow core on a flanged beam has been examined with a view to optimizing the beam section.

\section{BACKGROUND OF STUDY}

There has been a study of the behavior and strength of reinforced concrete T-beams before and after strengthening by using reinforced concrete jacket [5]. A study restored the full ultimate capacity of beams that failed by flexure and strengthened the cracked beam [6]. The results showed that repairing by reinforced jacketing can effectively restore more than

\footnotetext{
* Corresponding author, Tel: +234-802-339-5190
} 
$150 \%$ of the flexural capacity of the original beam. It has been shown that reinforced concrete and composite construction may be suitably combined to give a new structural material, composite reinforced concrete. The results obtained by finite element solution showed good agreement with experimental results. In an investigation of thirty-nine reinforced rectangular hollow core beams when the volume of concrete was kept constant and the depth and breadth dimensions varied [1], it was shown that,

$$
P_{u}=(0.1 D)^{1.5}-0.2 D+P^{\prime}
$$

Subject to; $0 \leq \mathrm{D} \leq 0.72 \mathrm{~b}$

In (1), $P_{u}$ is the ultimate failure load of hollow core beam, D is the diameter of hollow core ( $\mathrm{mm}), \mathrm{b}$ is the width of blind beam of equivalent concrete volume. (mm) and $P^{I}$ is the failure load of blind beam of equivalent concrete volume $(\mathrm{kN})$.

It has been shown that the fire resistance of hollow core flooring systems can be increased by using stiffer supporting beams at the end of the slabs and also by decreasing the spacing between the beams parallel to the hollow core units [7]. The results of shear strength tests on hollow core slabs have been reported [8]. An investigation on the positioning of hollow core in concrete beams showed that the core should be at the neutral axis [9]. Equations which predict the ultimate strength of beams with varying core diameter, subjected to combined torsion and bending, have been developed [10].

\section{MATERIALS AND METHODS}

Some methods of beam analyses include; finite element, finite difference, stiffness, energy and double integration. Moment of inertia method was chosen for this work because it readily suits the purpose and it takes into consideration, the sectional properties of the beam. The moment of inertia theorem was used to analyze the cross section and the parallel axis theorem was used to find the moment of inertia of each component area about the centroidal axis of the cross section which the neutral axis runs along. The double integration method for deflection of beams was used to derive the equation for the deflection at mid span which is the point for maximum bending for the simply supported beam point loaded at mid span. The hollow core position was maintained in the compression zone of the section. The corresponding neutral axis for every shift in hollow core position from the top of the beam section towards the neutral axis was determined.
The hollow core cross-sectional area and volume of all beams samples were kept constant such that only the geometry of the section was altered in order to effectively determine the optimum flange width and core position. The parameters obtained were used to prepare the samples experimentally according to the prescribed specifications $[11,12]$. The results were derived by direct observation of test samples in the laboratory using the Universal Testing Machine (UTM) with the setup shown in Figure 1. The materials used include fine aggregates obtained from the river, granite of average particle size of $20 \mathrm{~mm}$ and Ordinary Portland Cement conforming to the specification of BS 12 [13]. A Standard mix ratio of 1:2:4 with $\mathrm{w} / \mathrm{c}$ ratio kept constant at 0.5 was used. The hollow core was achieved by using standard circular PVC pipes. These were inserted during the casting of the concrete samples and withdrawn after 3 hours of casting them. Due to the significant difference between the theoretical and experimental results as determined by chi-square test, a correction factor was obtained using the graphs by determining the equation of the line of best fit which was incorporated in the theoretical analysis in order to develop the required model.

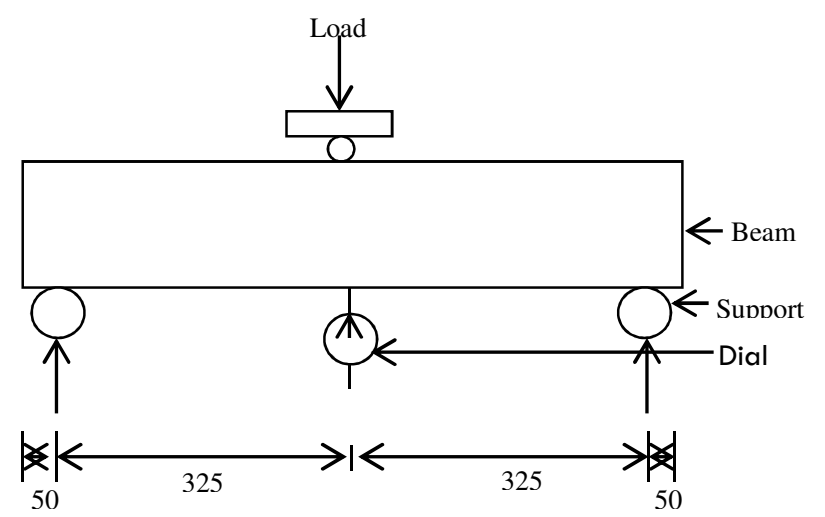

Figure 1: Experimental setup (Dimensions in mm)

\subsection{Background Theory}

The moment of inertia of a rectangular section is given as [14];

$$
I_{x x}=\frac{b d^{3}}{12}
$$

Here $b$ is the width of the beam and $d$ is the depth of the beam.

While that for a circular section is [14];

$$
I_{x x}=\frac{\pi}{64} d^{4}
$$

Here, $d$ is the diameter of the circular section.

The maximum deflection for a simply supported beam of span, L, which is loaded at the mid-span with a concentrated load, $P$, is given as [15]: 


$$
\delta=\frac{P L^{3}}{48 E I}
$$

Here, $P$ is the failure load, $L$ is the span of the beam, $E$ is the Young's modulus of the beam material and $I$ is second moment of area or moment of inertia of the beam.

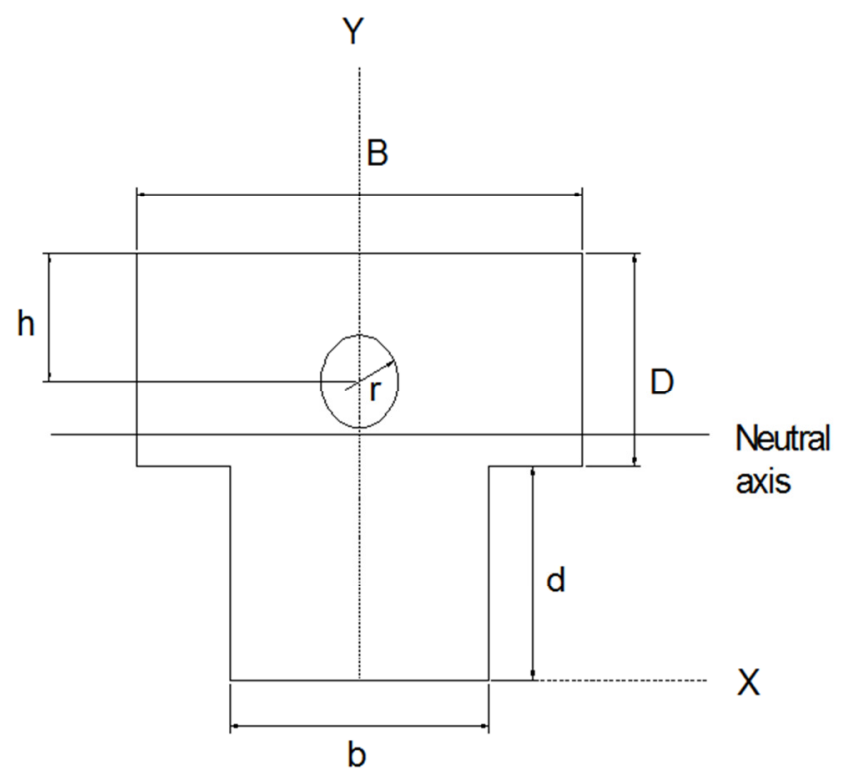

Figure 2: Flanged section with hollow core

The centroidal position of the section relative to the $y$ axis is determined as;

$$
\bar{\chi}=\frac{\sum a x}{\sum a}=\frac{a_{1} x_{1}+a_{2} x_{2}-a_{3} x_{3}}{a_{1}+a_{2}-a_{3}}
$$

In (5), $a_{1}$ is the area of the flange, $a_{2}$ the area of the web and $x_{1}, x_{2}$ and $x_{3}$ are the respective distance of centroid of each area in composite shape to the $y$ reference axis.

Similarly, the centroidal position of the section relative to the $\mathrm{x}$ axis is determined as;

$$
\bar{y}=\frac{\sum a y}{\sum a}=\frac{a_{1} y_{1}+a_{2} y_{2}-a_{3} y_{3}}{a_{1}+a_{2}-a_{3}}
$$

In (6), $y$ is the distance from centroid of each area in composite shape to the $\mathrm{x}$ reference axis. From parallel axis theorem, when the axis is moved through a distance, $d$. The moment of inertia about the new axis is determined as [12];

$$
I_{x c}=I_{x}+a d^{2}
$$

The equation for the centroid axis of the beam can be obtained as:

$$
\bar{y}=\frac{a_{1}\left(\frac{d}{2}+d\right)+a_{2}\left(\frac{d}{2}\right)-a_{3}(D+d-h)}{a_{1}+a_{2}-a_{3}}
$$

In (8), D is the flange thickness, $d$ the web thickness and $h$ is the distance from the remote edge of the flange to the centroid of the circular core.

Substituting (8) into (7), the equation for the moment of Inertia of the beam can be obtained by:

$$
\begin{aligned}
& I_{x c}=\left\{\frac{B D^{3}}{12}+a_{1}\left(\frac{d}{2}+d-\overline{\mathrm{y}}\right)^{2}\right\} \\
& +\left\{\frac{b d^{3}}{12}+a_{2}\left(\frac{d}{2}-\overline{\mathrm{y}}\right)^{2}\right\} \\
& -\left\{\frac{\pi r^{4}}{2}+a_{3}(D+d-h-\overline{\mathrm{y}})^{2}\right\}
\end{aligned}
$$

Here, $B$ is the width of the flange and $b$ is the width of the web.

Substituting relevant quantities obtained for the hollow core section in Figure 1 into equation (8), the equation for the centroid of axis of the beam becomes;

$$
\bar{y}=\frac{B D\left(\frac{D}{2}+d\right)+b d\left(\frac{d}{2}\right)-\pi r^{2}(D+d-h)}{B D+b d-\pi r^{2}}
$$

Here, $r$ is the radius of the hollow core. Hence;

$$
\bar{y}=\frac{\left(\frac{B D^{2}}{2}+B D d+\frac{b d^{2}}{2}\right)-\pi r^{2}(D+d-h)}{B D+b d-\pi r^{2}}
$$

and,

$$
\begin{aligned}
& I_{x c}=\frac{B D^{3}}{12}+B D\left(\frac{D}{2}+d-\overline{\mathrm{y}}\right)^{2}+\frac{b d^{3}}{12}+b d\left(\frac{d}{2}-\overline{\mathrm{y}}\right)^{2}-\frac{\pi r 4}{2}-\pi r^{2}(D+d-h-\overline{\mathrm{y}})^{2} \\
& I_{x c}=\frac{B D^{3}}{12}+B D^{2} d+\frac{B D^{3}}{4}-B D^{2} \overline{\mathrm{y}}+B D d^{2}+B D \overline{\mathrm{y}}^{2}+\frac{b d^{3}}{12}+\frac{b d^{3}}{4}-b d^{2} \overline{\mathrm{y}}+ \\
& +b d \overline{\mathrm{y}}^{2}-2 B D d \overline{\mathrm{y}}-\frac{\pi r^{4}}{2}-\pi r^{2} D^{2}-2 \pi r^{2} D d+2 \pi r^{2} D h+2 \pi r^{2} D \overline{\mathrm{y}}+ \\
& +2 \pi \mathrm{r}^{2} d \overline{\mathrm{y}}+2 \pi \mathrm{r}^{2} d h-2 \pi r^{2} \mathrm{~h} \overline{\mathrm{y}}-\pi r^{2} h-\pi r^{2} d^{2}-\pi r^{2} \overline{\mathrm{y}}^{2}
\end{aligned}
$$

Collecting like terms and substituting the value of $\bar{y}$ in (11) into equation (13); 


$$
\begin{aligned}
& I_{x c}=\frac{B D^{3}}{3}+B D^{2} d+B D d^{2}+\frac{b d^{3}}{3}-\frac{\pi r^{4}}{2}-\pi r^{2} D^{2}-2 \pi r^{2} D d+2 \pi r^{2} D h+ \\
& +2 \pi r^{2} d h-\pi r^{2} h^{2}-\pi r^{2} d^{2}-\left[\frac{\frac{B D^{2}}{2}+B D d+\frac{b d^{2}}{2}-\pi r^{2}(D+d-h)}{B D+b d-\pi r^{2}}\right]\left[B D^{2}+\right. \\
& \left.+b d^{2}+2 B D d-2 \pi r^{2} D-2 \pi r^{2} d+2 \pi r^{2} h\right]+ \\
& +\frac{\left[\left(\frac{B D^{2}}{2}+B D d+\frac{b d^{2}}{2}\right)-\pi r^{2}(D+d-h)\right]^{2}}{B D+b d-\pi r^{2}}
\end{aligned}
$$

Substituting $\mathrm{I}_{\mathrm{xc}}$ into equation (5) we obtain;

$$
\begin{aligned}
& \delta=\frac{P L^{3}}{48 E}\left\{\frac{B D^{3}}{3}+B D^{2} d+B D d^{2}+\frac{b d^{3}}{3}-\frac{\pi r^{4}}{3}-\pi r^{2} D^{2}-2 \pi r^{2} D d+2 \pi r^{2} D h+\right. \\
& +2 \pi r^{2} d h-\pi r^{2} h^{2}-\pi r^{2} d^{2}-\left[\frac{\left(\frac{B D^{2}}{2}+B D d+\frac{b d^{2}}{2}\right)-\pi r^{2}(D+d-h)}{B D+b d-\pi r^{2}}\right]\left[B D^{2}+b d^{2}+\right. \\
& \left.\left.2 B D d-2 \pi r^{2} D-2 \pi r^{2} d+2 \pi r^{2} h\right]+\frac{\left[\left(\frac{B D^{2}}{2}+B D d+\frac{b d^{2}}{2}\right)-\pi r^{2}(D+d-h)\right]^{2}}{B D+b d-\pi r^{2}}\right\}^{-1}
\end{aligned}
$$

Experimental results were obtained from direct observation of a dial gauge directly attached at the bottom of the test specimens in the laboratory using a Universal Testing Machine. Readings were taken from the gauge at $1 \mathrm{kN}$ intervals as the beams were stressed by point loading at midspan, until their ultimate failure load. The beams failed by cracking initiated at the bottom fibre and gradually propagated to the top fibre. The specimens were made in the same specifications as the theoretical parameters with a hollow core position of $46 \mathrm{~mm}$ obtained from the model.

\section{RESULTS AND DISCUSSION}

The results were obtained by imputing parameters of the beam samples into the developed model which gave the theoretical results and by direct readings taking by observation of a dial gauge attached to the bottom of the test specimens, which were subjected to point loading at midspan, in the laboratory. The chisquare test was used to analyze the theoretical results and it showed there was no significant difference between results obtained. The experimental results showed a fluctuation in the deflection values observed as the flange width was increased while a steady increase of deflection was seen as the point load was increased until failure. It can be seen that as the flange width of the T-Beams increased, the web width was correspondingly reduced thereby reducing the crack width of the tension zone of the beam, which may have contributed to the decreasing failure load as flange width increased.

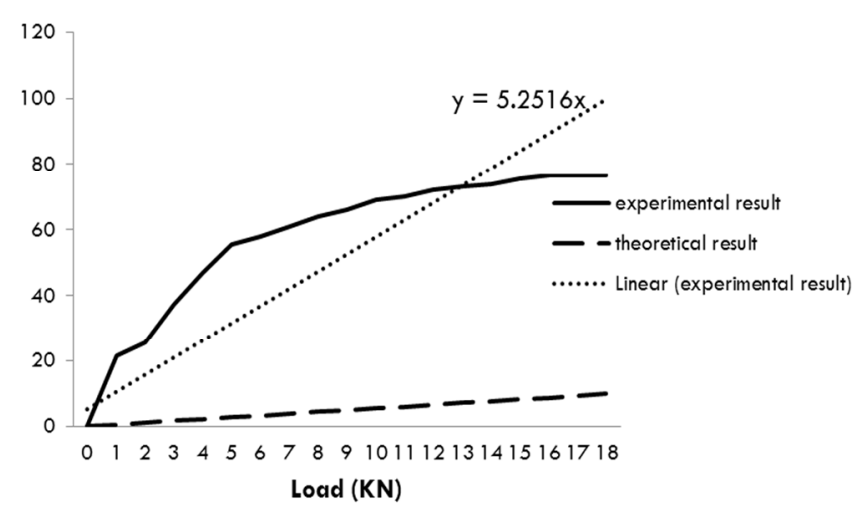

Figure 3: Load deflection relationship for 46mm core position and 150mm flange width

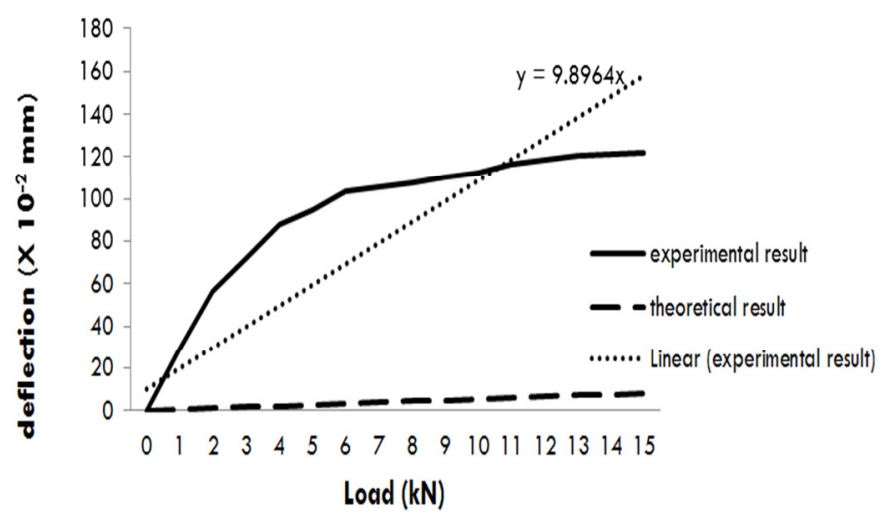

Figure 4: Load deflection relationship for 46mm core position and 160mm flange width

Vol. 34, No. 2, April 2015 


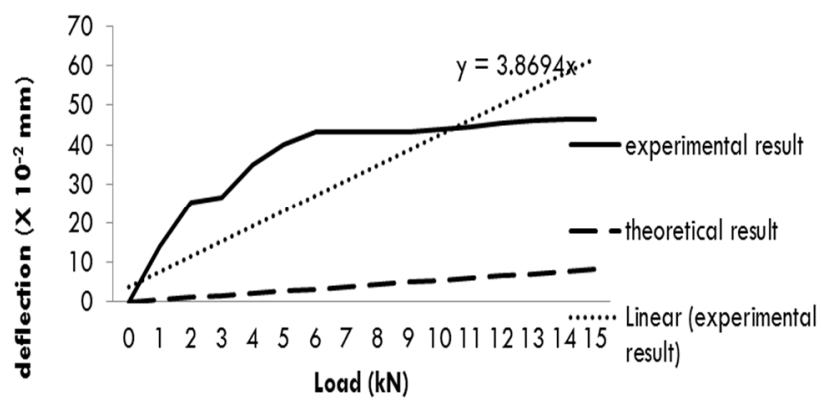

Figure 5: Load deflection relationship for 46mm core position and $170 \mathrm{~mm}$ flange width

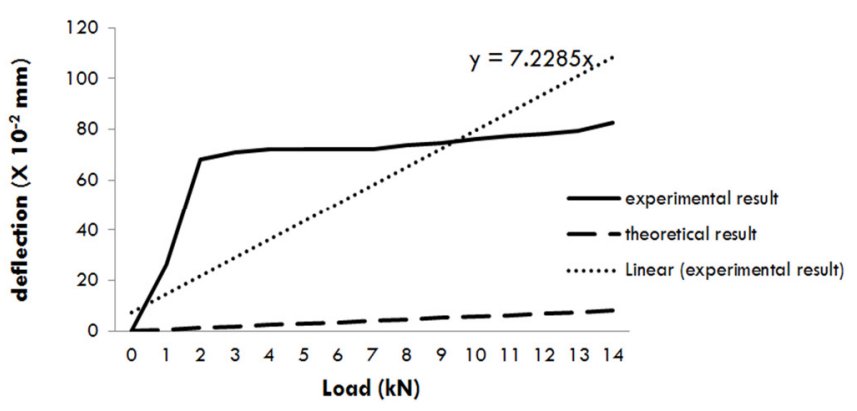

Figure 7: Load deflection relationship for 46mm core position and $190 \mathrm{~mm}$ flange width

The results in Figures3-7 showed that there was an increase in deflection as the point load was increased. This behaviour of the beams was in agreement with the literature [14] as they obeyed Hooke's law. However, as the flange width was increased, there was an initially straight path during which Hooke's law was obeyed, beyond which a curve was developed in all the samples. This curve may have been due to the development of some irrecoverable deformations [14]. At failure, maximum deflections of $0.95 \mathrm{~mm}$, $1.48 \mathrm{~mm}, 0.58 \mathrm{~mm}, 1.48 \mathrm{~mm}$ and $1.01 \mathrm{~mm}$ were obtained for beams with $150 \mathrm{~mm}, 160 \mathrm{~mm} 170 \mathrm{~mm}$, $180 \mathrm{~mm}$ and $190 \mathrm{~mm}$ flange widths respectively. These results also show a similarity between theoretical and experimental results as they were same in pattern but differ in gradient. The results showed that as the flange width was increased from $150 \mathrm{~mm}$ to $190 \mathrm{~mm}$, the failure load decreased from $18 \mathrm{kN}$ in Figure 3 through $15 \mathrm{kN}$ in Figures 4 and 5 to $14 \mathrm{kN}$ in Figures 6 and 7. A comparison of the results shown in the figures 3 to 7 show that the beam with $170 \mathrm{~mm}$ flange width, $46 \mathrm{~mm}$ core position and $0.58 \mathrm{~mm}$ deflection at a failure load of $15 \mathrm{kN}$ (see Figure 5), was the optimal section, since it had the least coefficient of 3.87. This is reasoned to be due to the higher moment of inertia of this section when compared to those with increased flange widths. This is as a result of the higher moment of inertia of this section compared to those with

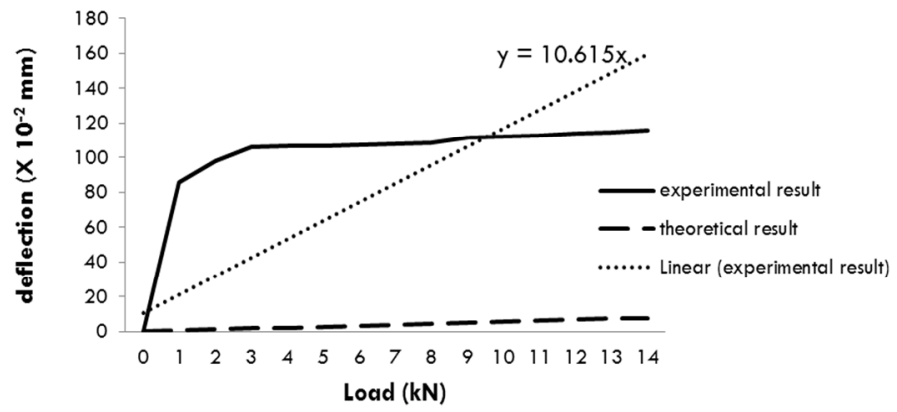

Figure 6: Load deflection relationship for 46mm core position and $180 \mathrm{~mm}$ flange width

increasing flange widths. This result compares favorably with the literature $[1,2,4]$.

\section{CONCLUSION AND RECOMMENDATION}

In practice, Hollow cores have been introduced in structural elements such as columns and slabs, in buildings and in bridge decks. These have sometimes served as mechanical or electrical conduits. The present work has provided a clearer understanding of the effect of these cores as they vary in diameter and position in the compression zone of flanged concrete beam sections. The optimum compression zone of the flanged hollow core beam has been determined. The beam with $170 \mathrm{~mm}$ flange width, $46 \mathrm{~mm}$ core position and $0.58 \mathrm{~mm}$ deflection at failure load of $15 \mathrm{kN}$ was the most optimal section. From these results, it is recommended that when hollow core concrete is used as investigated, the size of the hollow should not exceed $50 \%$ of the total web width and flange width could be up to $126.67 \%$ of the beam web width.

\section{REFERENCES}

1. Orie, O. U. and Alutu, O. E. "Flexural Characteristics of Reinforced Hollow Cored Concrete Beams Point Loaded at Mid-span", Nigerian Journal of Technological Development, Vol. 5, 2007, pp 30-38.

2. Ossai, G. I. Structural Characteristics of Unreinforced Hollow core Beams, M. Eng. Thesis, Department of Civil Engineering, University of Nigeria, Nsukka, 1988.

3. Mydin, M.A. O. and Ramli, M. "Rational Design of Hollow Core Planks for Fire Resistance", Advances in Applied Science Research, Vol. 3, Number 5, 2012, pp 2830-2836.

4. Orie, O. U. and Alile, O. M. "Effect of the Variation of Hollow Core Diameter in Rectangular Plain Concrete Beams", Journal of the Association of Mathematical Physics. Vol. 12, 2008, pp 79 - 86.

5. Al-Kuaity, A. S. "Strengthening of Reinforced Concrete T-beam by Jacketing", Journal of 
Engineering, Vol. 16, Number 3, 2010, pp. 57535775.

6. Israa, K. A., Nagham, T. H. and Waleed, A. W. "Investigation on the Behavior of Reinforced Concrete Beams using Non-linear three Dimensional Finite Element Model", Engineering and Technical Journal, Vol. 29, Number. 10, 2011, pp187- 191.

7. Chang, J. J. Computer simulation of hollowcore concrete flooring systems exposed to fire, $\mathrm{PhD}$ Thesis, Department of Civil Engineering, University of Canterbury, New Zealand, 2007.

8. Hawkins, N. M. and Ghosh, S.K. "Shear Strength of Hollow-core Slabs", PCI Journal, 2006, pp110-114.

9. Orie, O. U. "Effect of Core Position on the Failure Load of Hollow Core Concrete Beam using Moment of Inertia Theory", Journal of the Institution of Production Engineers, Vol. 12, 2010, pp 203-213.
10. Raugan, B.V. and Hall, A.S. " Studies on Prestress Concrete Hollow Beams in Combined Torsion and Bending", Magazine of Concrete, Vol. 31, Number 106,1979, pp 28-36.

11. British Standards Institution, BS 1881 part 109 "Specifications for Concrete Moulds", British Standards House, London, 1983.

12. British Standards Institution, BS EN 12390 part 1 "Testing Hardened Concrete", British Standards International, 1983.

13. British Standards Institute, BS 12 "Portland Cement (Ordinary and Rapid Hardening)", British Standards House, London, 1996.

14. Rhyder, G. H. Strength of Materials, Macmillan Educational Press Limited, London, 1982.

15. Khumi, R. S. Strength of Materials, Third edition, S. Chand Limited, New Delhi, 2005. 